\title{
DNA Immunotherapies for Type 1 Diabetes
}

\author{
Alice Li and Alan Escher \\ Additional information is available at the end of the chapter \\ http://dx.doi.org/10.5772/55727
}

\section{Introduction}

As per the American Diabetes Association, 2-3 million individuals in the United States have type 1 diabetes (www.medicinenet.com/script/main/art.asp?articlekey=159355), with 1 in every 400 to 600 children and adolescents affected by the disease in 2007. Furthermore, similar to other autoimmune diseases, allergies and asthma, the incidence of type 1 diabetes is on the increase at an alarming rate in industrialized countries for unknown reasons. Information released by the American Diabetes Association shows 23\% and 21\% increased rates of type 1 and 2 diabetes, respectively, from 2001 to 2009. The increase in incidence of type 1 diabetes is especially apparent in young children and has generated an urgent need for novel treatments that can safely control diabetes-causing inflammation, and alleviate the need for administration of exogenous insulin. Indeed, type 1 diabetes has been treated for almost a century in the same fundamental manner using daily insulin injections. Although it is a life-saving treatment and one of the most remarkable accomplishments of medicine, administration of exogenous insulin is still not a cure because it does not address the underlying autoimmunity that targets insulin-secreting beta cells. Because it is currently impossible to mimic regulation of physiological insulin levels faithfully, many type 1 diabetic individuals receiving standard of care are exposed to acute and chronic complications that cause increased morbidity and mortality. As a result, there have been intense efforts to develop immunotherapies that can eliminate or at least alleviate the need for exogenous insulin. In this case the goal is to arrest pathological autoimmunity that destroys beta cells so that the cells can regain function, and possibly proliferate and regenerate.

Two major immunotherapeutic paths have been taken. The first path relies on different forms of systemic suppression of inflammation that inhibit effector T lymphocytes in a non-specific manner. Serious side effects associated with the use of systemic immunotherapies are increased risks of cancer and infection resulting from the decreased activity of effector cells involved in beneficial destructive immune responses against cancer cells and pathogens. These 
side effects have been observed with broadly acting immunosuppressants used to prevent organ transplant rejection, which have been also investigated for treating type 1 diabetes [1, 2]. Serious side effects can also be seen, albeit to a lesser degree, with more specific agents like antibodies that target specific molecules involved in inflammation [3, 4]. In contrast, the second immunotherapeutic path is based on administration of a self-antigen synthesized by pancreatic beta cells that is a target of pathological autoimmunity, i.e., an autoantigen. This path is thought to be safer because it aims to induce a regulatory immune response that targets the inflamed islets. Here the goal is to manipulate endogenous immune mechanisms of homeostasis that can re-establish some form of tolerance to the chosen autoantigen, as well as to other neighboring beta cell autoantigens through a mechanism known as "by-stander suppression" [5]. Accordingly, it is anticipated that pathological autoimmunity and inflammation of islets can be stopped in an organ-specific manner that does not impair the immune system.

In this chapter, we will review how plasmid deoxyribonucleic acid (DNA) has been used as an immunotherapeutic vector platform to treat type 1 diabetes through each immunotherapeutic path. For the purpose of this review, we have called the first path "gene-based immunotherapy", meaning that plasmid DNA does not encode a known autoantigen, and the second path "DNA vaccine immunotherapy" meaning that a beta cell autoantigen is encoded by plasmid DNA (Figure 1). In other words, gene-based immunotherapy relies on the inherent function of a product encoded by plasmid DNA that can in turn affect cell function. In contrast, DNA vaccine immunotherapy relies on the tolerogenic immune response induced directly by the autoantigen after its processing by immune cells. As we shall see, some DNA vaccine immunotherapies have also a gene-based immunotherapy component that acts as a molecular adjuvant to promote tolerogenic immune responses. Nevertheless, in all cases synthesis of the molecule encoded by plasmid DNA, which is almost always a protein, starts after delivery of the plasmid DNA and its uptake by cells.

Plasmid DNA has several notable advantages compared to other vectors and therapeutic molecules. For example, it consists of relatively low molecular weight circles of double stranded DNA that can be readily isolated from bacteria in a generic and cost-effective manner. In addition, plasmid DNA permits rapid turnaround when developing new candidate products, refrigeration-free storage, and synthesis over time of a chosen antigen in its native conformation. Furthermore, plasmid DNA can be given in repeat doses within short periods of time without inducing an immune response to vector and other side effects. This is in contrast with viral-based vaccines that can induce immune responses to vector and protein/ peptides that can cause anaphylaxis [6,7].

Plasmid DNA can be delivered either as "naked" DNA or packaged into molecular scaffolds like liposomes, cationic lipids, virosomes, and polymer-based nano- and micro-particles to increase efficacy of delivery to cells [8]. Although they may sometime have pro-inflammatory properties that can be detrimental to controlling inflammation, these particles have been used to induce immune tolerance with plasmid DNA. For example, chitosan-DNA nanoparticles encoding an ovalbumin antigen are tolerogenic when delivered orally [9].

Indeed, route of delivery can play a significant role in the type and strength of immune responses induced by DNA vaccines in animal models [10,11]. In humans, two microgram of 
a DNA vaccine for treatment of melanoma delivered with gold particles into skin was found to be as efficacious as 1000 microgram injected intramuscularly [12]. These results illustrate the significant impact that choice of route and method of delivery of a DNA vaccine can have not only on efficacy, but also on cost of treatment. Other delivery routes like intravenous, nasal, and sublingual have also been investigated [13]. Post delivery, expression of coding sequences in plasmid DNA results in significant levels of protein production that may persist for six weeks and longer without serious side effects in human patients [14, 15].

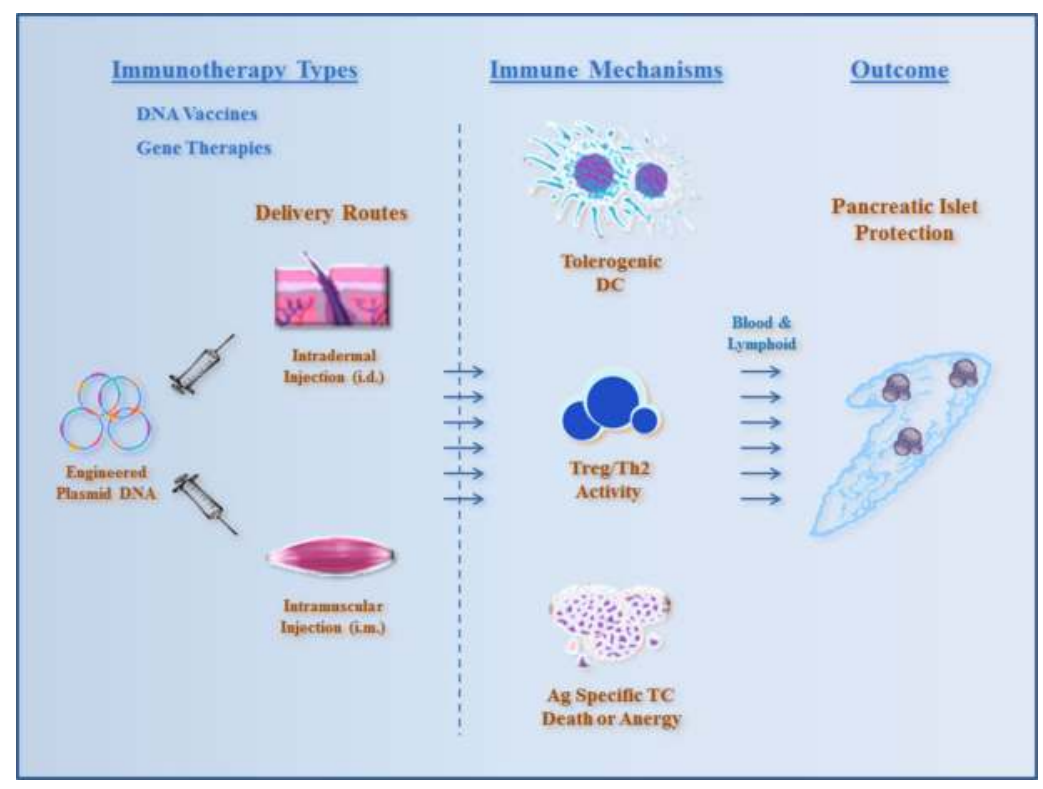

Figure 1. Plasmid DNA Immunotherapy for Type 1 Diabetes. Plasmid DNA immunotherapy for type 1 diabetes can be divided into two categories: DNA vaccines and gene therapies. Plasmid DNA can be delivered using different routes, for example, the intradermal and intramuscular routes. The therapies can induce tolerogenic dendritic cells (DC), T regulatory cells (Treg), and death/anergy of T effector cells (Teff) which are the main cause of pancreatic islet destruction.

DNA vaccination was originally investigated to induce immunogenic responses to pathogens and cancer cells, but it has increasingly been applied to the induction of immune tolerance for treatment of autoimmune diseases like type 1 diabetes. DNA vaccines and other gene-based vaccines belong to a third generation of vaccines after live and attenuated whole organism vaccine and recombinant protein vaccines. These vaccines can be used to either prevent (prophylactic vaccine) or treat (therapeutic vaccine) disease depending on their potency, in which prevention is generally easier to achieve than treatment. Recent reports of beneficial results in different clinical trials using delivery of autoantigens indicate that DNA vaccination is reaching a stage where we are likely to see accelerated development of a therapeutic future for vaccines targeting a variety of autoimmune diseases. In the case of type 1 diabetes, early results using a DNA vaccine encoding insulin have shown promise in humans. In addition, 
DNA vaccines encoding human heat shock protein 60 and glutamic acid decarboxylase 65 have also shown efficacy in preclinical trials and are reviewed in this chapter.

In contrast to DNA vaccine immunotherapy, gene-based immunotherapy involves delivery of genetic material by a plasmid vector into a cell, tissue or organ with the aim of improving the clinical status using the function of the encoded product, instead of its properties as an antigen. Gene-based immunotherapy includes delivery of anti-inflammatory cytokines, chemokines, and other factors to modulate the activity of immune cells [16, 17].

\section{Gene-based immunotherapies}

Several pre-clinical trials have used plasmid DNA-based gene therapies in experimental models of autoimmune type 1 diabetes. These strategies involve plasmid DNA designed to weaken pre-existing beta-cell autoimmunity through delivery of anti-inflammatory cytokines, chemokines, and other immune cell manipulating agents. The goal of these therapies is to reduce clinical symptoms and autoimmune outcome.

\subsection{Cytokine gene therapies}

Cytokine gene therapies are strategies that use engineered plasmid DNA to produce therapeutic immune cytokines, which are a group of immune active molecules secreted by different cells of the body. Some of these cytokines are considered beneficial for the suppression of autoimmunity, and thus are applied to disease models to reduce clinical symptoms and improve therapeutic effects. Studies of animals with spontaneous autoimmune diabetes have revealed that an important group of autoreactive $T$ cells that mediates islet beta-cell destruction belongs to the T helper-1 type effector cell subset, and produces cytokines like interleukin-2 and interferon-gamma. On the other hand, regulatory $\mathrm{T}$ cells that control effector cells can secrete interleukin-4, interleukin-10, and transforming growth factor-beta.

One of the earliest applications of cytokine-engineered plasmid DNA was gene-gun delivery of murine interleukin- 4 to prevent spontaneous type 1 diabetes [18]. The plasmid DNA was delivered as three times two microgram within 4 weeks into 3-week-old nonobese diabetic mice, which is the animal model system closest to human type 1 diabetes. Type 1 diabetes incidence was reduced from $90 \%$ in controls to $20 \%$ at 34 weeks of age, and was associated with $\mathrm{T}$ helper-2 type immune responses in the periphery and pancreas of mice. Two other reports have shown that systemic delivery of plasmid DNA constructs coding for interleukin-4 can prevent insulitis, which is an inflammatory sign of immune cell infiltrating pancreatic islets in nonobese diabetic mice $[19,20]$. However, contradictory results have been reported. For example, a report indicates that intramuscular electroporation delivery of $50 \mu \mathrm{g}$ plasmid DNA encoding interleukin- 4 accelerated spontaneous type 1 diabetes in nonobese diabetic mice [21].

In addition to interleukin-4, interleukin-10-encoded plasmid DNA alone was also tested for its diabetic suppressive effects. The plasmid DNA was delivered intramuscularly twice for a total of 200 microgram into 3 and 5 week old female nonobese diabetic mice [22]. Although 
the severity of insulitis at 13 weeks of age was not improved, the incidence of diabetes was markedly reduced to $50 \%$ at 35 week old compared to $90 \%$ with control mice. These results show that the progression of autoimmune disease in mice can effectively be suppressed by intramuscular DNA injection coding for anti-inflammatory cytokines alone. When the same interleukin-10 encoded plasmid DNA was combined with a cationic polymeric carrier, systemic administration could reduce the severity of insulitis in NOD mice markedly $(15.7 \%)$ compared with that of naked DNA injection (34.5\%) and non-treated controls $(90.9 \%)$, suggesting an increased protective effect of the polymeric carrier in vivo [23].

Another report investigating the immune effects of interleukin-10 DNA showed that systemic intramuscular administration of 200 microgram interleukin-10 plasmid DNA could alleviate blood glucose and insulitis in a streptozotocin induced diabetic mouse model up to day 28 post injection [24]. In this model, pancreatic interleukin-1b and tumor necrotic factor-alpha gene expression, serum interferon-gamma concentration, and the numbers of CD4+ and CD8 ${ }^{+}$lymphocytes were decreased on day 28. A similar interleukin-10 construct was modified by introducing nuclear factor kappa-B (NF-kB) binding sites into plasmid DNA to facilitate nuclear transport of the plasmid after delivery into the cell [25]. A single injection of 50 microgram of the plasmid using polyethylenimine as a gene carrier in 5 week old mice reduced the degree of insulitis and serum glucose levels in 100\% of mice compared to $40 \%$ of the control mice at 32 weeks of age. These results illustrate how plasmid DNA can be easily modified in a generic manner to improve therapeutic efficacy.

As mentioned previously, nanoparticle technology has been used to condense plasmid DNA into nanometer-size complexes to improve delivery. An interleukin-10 encoding plasmid DNA was assembled into a cationic nanoparticle complex, and a single dose of 50 microgram DNA was delivered intramuscularly into streptozotocin-induced diabetic mice [26]. Animals showed higher serum levels of interleukin-10, suppression of interferon-gamma level, reduction of islet insulitis, and lower blood glucose levels compared to those treated with interleukin-10 plasmid alone or the nanoparticle alone up to week 6 post injection. Histology of muscle showed that nanoparticles were biocompatible and did not cause a chronic inflammatory response.

In addition to their use alone, delivery of both interleukin- 4 and interleukin-10 DNA has also been investigated. Combined delivery into nonobese diabetic mice of the two plasmid DNA constructs encoding interleukin-4 and interleukin-10 (25 $\mu \mathrm{g}$ each) was done intravenously using a degradable, cationic polymeric carrier, poly (alpha-(4-aminobutyl)-L-glycolic acid) [27]. Overexpression of the two cytokine messenger RNAs was confirmed in the liver of mice 5 days after delivery. Six weeks after injection, 75\% of observed islets were intact compared with less than $3 \%$ in the control group, and development of diabetes was prevented in $75 \%$ of treated animals at 30 weeks of age, compared to $20 \%$ in control mice receiving plasmid DNA coding for a single cytokine or vector control alone. The results indicated that the interleukin- 4 and interleukin-10 plasmid DNAs had synergistic effects on the prevention of autoimmune diabetes. A report from the same research group showed that a 'chimeric' plasmid expressing both of the interleukin- 4 and interleukin- 10 under controls of two CMV promoters could also reduce insulitis in the same system [28]. 
More recently, a research group also reported packaging plasmid DNA constructs coding for interleukin- 4 and interleukin-10 into cationic nanomicelles to prevent type 1 diabetes [29]. A single intramuscular dose of 50 microgram of the complex reduced levels of blood glucose and insulitis up to 6-week post delivery in 5-week-old streptozotocin-induced diabetic mouse. It was found that levels of diabetes-associated cytokines like tumor necrotic factor-alpha and interferon-gamma were also reduced, which suggested suppression T helper- 1 effector cells by the cytokine/cationic nanomicelle complex therapy. Notably, plasmid DNA coding for interleukin-4 and interleukin-10 has also been used as adjuvant to promote the therapeutic effect of DNA vaccines in a murine model for type 1 diabetes, which will describe later in this chapter in the 'Glutamic Acid Decarboxylase DNA Vaccines' section.

In addition, a number of studies have reported that injection of plasmid DNA coding for cytokines normally considered pro-inflammatory can prevent diabetes. These results reflect the multifaceted role of cytokines on immune response [30], which could be dependent on dosage and time of administration. For example, administration of interleukin-18, also known as interferon-gamma inducing factor, can prevent diabetes in NOD mice [31, 32]. However, it was also shown that intramuscular electroporation of $2 \times 100$ microgram plasmid DNA coding for interleukin-18 into 4-6-week-old nonobese diabetic mice aggravates diabetes [33]. Another report showed that intraperitoneal administration of 30 microgram of plasmid DNA encoding interferon-gamma promotes insulitis in reovirus type- 2 induced diabetic mice compared to controls [34]. This is in contrast with another report showing that injection of interleukin-12 induces interferon-gamma that prevents diabetes in NOD mice [35]. Together, these results suggest that there is risk associated with direct delivery of cytokines for the treatment of type 1 diabetes. This possibility is suggested by a phase I clinical trial where new onset patients with type 1 diabetes received a combination treatment of interleukin-2 and the immunosuppressant rapamycin. The treatment had shown efficacy in preventing disease in mice, but it accelerated disease in humans [2].

\subsection{Chemokine gene therapies}

Chemokines are a family of small chemotactic cytokines secreted by cells [36]. Their name is derived from their ability to induce directed chemotaxis, or directed cell migration, in responsive cells. Some chemokines are considered pro-inflammatory and can be induced during an immune response to recruit cells of the immune system to a site of infection, while others are considered homeostatic and are involved in controlling the migration of cells during normal tissue maintenance and inhibiting abnormal inflammation like pathological autoimmune response.

Chemokines are involved in pathogenesis of autoimmune disease because they can selectively recruit various subsets of immune lymphocytes $[37,38]$. Based on structural motifs near their $\mathrm{N}$-terminal cysteine residue $[\mathrm{C}]$, chemokines are divided into four subfamilies, termed $\mathrm{CXC}$, CX3C, C, and CC. The function of chemokines is modulated by the type of chemokine receptors they bind to as ligands on the surface of cells, and studies have shown that chemokines and chemokine receptors are involved in the pathogenesis of autoimmune diseases like type 1 
diabetes. Chemokine gene therapies for type 1 diabetes use anti-inflammatory chemokines as well as inhibitors of pro-inflammatory chemokine binding.

With regard to blocking strategies, CXC ligand-10 is an example of a chemokine associated with the pathogenesis of various T helper-1 dominant responses involved in autoimmune diseases, e.g., experimental autoimmune encephalomyelitis, rheumatoid arthritis, and type 1 diabetes. It was found that, in type 1 diabetic adult patients, elevated levels of serum CXC ligand-10 are associated with high-risk of disease in latent diabetic subjects [39]. This finding was translated in animal models where blockade or neutralization of the CXC ligand-10 can prevent type 1 diabetes in nonobese diabetic mice [40]. In virus-induced diabetic mice, virus infection results in rapid and differential expression of CXC receptor-3 and CXC ligand-10, which plays a dominant role in programming the ensuing autoimmune disease [41]. The blockade of CXC ligand-10 by using anti CXC ligand-10 monoclonal antibodies successfully aborts severity of antigen-specific injury of pancreatic beta cells and abrogates type 1 diabetes. Mechanistically, the blockade impedes the expansion of peripheral antigen-specific T effector cells and hinders their migration into the pancreas. A similar effect of the antibodies was confirmed in a cyclophosphamide accelerated model of type 1 diabetes [40].

Based on these reports, plasmid DNA encoding the CXC ligand-10 was constructed to induce production of anti-CXC ligand-10 antibodies in the host [42]. The aim was to avoid side-effects associated with direct injection of antibodies. Intramuscular electroporation of 100 microgram of the plasmid DNA at 4 and 6 weeks of age induced synthesis of anti CXC ligand-10 antibodies in vivo, and suppressed the incidence of spontaneous diabetes which went from $75 \%$ in control mice down to $25 \%$ in treated mice at 30 weeks of age. Although this treatment did not inhibit insulitis or alter the immunological response, it enhanced the proliferation of pancreatic beta cells and resulted in an increase of beta-cell mass.

A subsequent report from the same research group showed that combining complete Freund's adjuvant with plasmid DNA encoding the CXC ligand-10 could reverse diabetes [43]. Intramuscular electroporation combined with complete Freund's adjuvant was used to treat newonset female nonobese diabetic mice with blood glucose levels higher than $250 \mathrm{mg} / \mathrm{dL}$. Diabetes incidence was reduced from $70 \%$ in control mice to $20 \%$ in treated mice 10 weeks after plasmid DNA delivery. In contrast, mice receiving complete Freund's adjuvant and control plasmid DNA did not show disease reversal. In mice that were treated successfully, residual beta-cell mass was significantly increased, and some beta-cells were in a proliferative state. Although systemic cytokine profiles were unaffected, the frequency of regulatory T cells expressing CXC receptor-3 was significantly increased in local pancreatic lesions and possibly associated with the regulation of anti-islet autoimmunity.

Another research group found that intra-pancreatic CC ligand-4 levels are increased in a model of diabetes protection by interleukin- 4 treatment in female nonobese diabetic mice [44]. The protective effect of CC ligand-4 was confirmed by abrogation of diabetes suppression after injection of anti-CC ligand-4 antibodies [45]. These result led to studies using CC ligand-4encoded plasmid DNA therapy which showed that gene-gun delivery of 1 microgram of the plasmid DNA protects against type 1 diabetes in NOD mice, with diabetes rates reduced from $75 \%$ in control mice to $30 \%$ at 35 weeks of age when treated weekly from week 3 to 14 , and 
from $80 \%$ in control mice down to $30 \%$ when treated weekly from week 9 to 14 [45]. Data also indicated that plasmid DNA delivery could both prevent and treat type 1 diabetes. This protection was associated with a Thelper-2-like response in the spleen and pancreas, decreased recruitment of activated CD8 $\mathrm{T}$ cells to islets accompanied by diminished CC receptor- 5 expression on CD8 T cells, and increased regulatory $\mathrm{T}$ cell activity in the draining pancreatic lymph nodes.

To summarize, plasmid DNA encoding CC ligand-4 and CXC ligand-10 have been tested for their type 1 diabetic suppressive effects in spontaneous diabetic mouse models. Diabetes suppression is associated with decreased CD8 T lymphocyte activity and increased CD4 T regulatory cell activity. These results suggest a possible clinical application of chemokine ligand gene therapies, although they are anticipated to have possible side effects associated with systemic immunotherapies.

\subsection{Other cell-manipulating gene therapies}

Several immune cell populations have deficiencies in type 1 diabetes, such as CD4 T lymphocytes, CD8 T lymphocytes, B lymphocytes, dendritic cells, macrophages, and NK cells in both nonobese diabetic mice and human patients [46,47]. The goal of cell-manipulating gene therapy is to increase the diabetic suppressive function of cells like T regulatory or T helper-2 lymphocytes, which are considered important not only for therapeutic purposes, but also for playing a determining role in the development of type 1 diabetes.

As mentioned at the beginning of this chapter, type 1 diabetes is a $\mathrm{T}$ helper-1-mediated autoimmune disease and strategies suppressing the function of these cells can be expected to have an impact on disease progression. One of these strategies is the delivery of galectin-9, a carbohydrate-binding protein that regulates $\mathrm{T}$ helper-1 cells and induces their apoptosis through the galectin-9 receptor. Apoptosis, or programmed-cell-death, is a constantly ongoing process in steady state in vivo and helps maintain tissue and immune homeostasis. Mice treated with plasmid DNA coding for galectin-9 were significantly protected from diabetes: intravenous delivery of $2 \times 100$ microgram bi-weekly protected $85 \%$ of mice from diabetes versus $55 \%$ in controls [48]. Analysis of immune responses showed that the Thelper- 1 cell population was markedly decreased in spleen, pancreas, and pancreatic lymph nodes of treated NOD-T1/2 double transgenic diabetic mice, indicating a suppressive role of galectin- 9 on pathogenic $\mathrm{T}$ helper-1 cells. Splenocytes from treated mice were also less responsive to mitogenic stimulation than splenocytes from the control group. Data indicated that galectin-9 DNA may downregulate Thelper-1 immune response in diabetic mice and could be used as a therapeutic agent in autoimmune diabetes.

In contrast with galectin-9, decoy receptor 3 inhibits apoptosis. The membrane protein is a member of the tumor necrosis factor receptor superfamily, and regulates immune responses by neutralizing apoptotic signals transmitted through CD95 (Fas receptor), lymphotoxin betareceptor, and death receptor 3 on target cells. As a result, transgenic expression of decoy receptor 3 in pancreatic beta cells protects nonobese diabetic mice from autoimmune diabetes [49]. When decoy receptor 3 is delivered systemically as plasmid DNA, it inhibits insulitis and diabetes by modulating immune responses. For example, four weekly intravenous injections 
of 100 microgram of plasmid DNA coding for decoy receptor 9 into nonobese diabetic mice was reported to reduce diabetes incidence from $90 \%$ in controls to $30 \%$ when treated at 4 weeks of age, $45 \%$ (started at 7 week old), and $70 \%$ (as Fc-fusion form, started at 12 week old) in 35week-old female nonobese diabetic mice [50]. Treated mice showed less splenocyte proliferation and adoptive transfer of the cells ameliorated diabetes. Treated NOD-T1/2 mice had reduced T helper-1, T helper-17, and increased Thelper-2 immune responses in vivo. Data also indicated that immune modulation by decoy receptor 3 may have been the result of differentiation and maturation of dendritic cells that subsequently regulated $\mathrm{T}$ effector differentiation and function.

Cell migration is another process that plays a role in pancreatic beta cell destruction. In this regard, plasmid DNA coding for CD44, which is a protein associated with cell migration and delivery of apoptotic signals by inflammatory cells, was investigated for the suppression of diabetes. It was found that subcutaneous implants of a silicone tube filled with wound dressing sponge carrying CD44 encoded plasmid DNA could attenuate diabetes in a transfer model [51]. Diabetes was induced in male nonobese diabetic mice by transfer of diabetogenic splenocytes from female diabetic mice and was reduced from $90 \%$ in controls to $20-30 \% 12$ weeks after two implants. Here the mechanism of treatment was not thought to be strictly a gene therapy effect, but rather induction of anti-CD44 antibodies that inhibited CD44 function.

An increasing body of evidence points to a possible relationship between the central nervous system and diabetes [52]. For example, the pancreatic autoantigen glutamic acid decarboxylase is an enzyme responsible for synthesis of the neurotransmitter gamma-aminobutyric acid (GABA) in the peripheral and central nervous system. Notably, at least two neurotransmitterrelated peptides have been used successfully as plasmid DNA immunotherapies for type 1 diabetes.

The first peptide is calcitonin gene-related peptide (CGRP), which has been found to play an important role in the regulation of $\mathrm{T}$ lymphocytes and in protecting cells from reactive oxygen species. It was found that a single injection of 200 microgram plasmid DNA encoding the peptide delivered intramuscularly using electroporation could significantly ameliorate hyperglycemia and insulin deficiency [53]. The treatment decreased diabetes incidence from $73 \%$ in controls to $23 \%$ at 28 days post delivery in a streptozotocin-induced diabetic model. The gene transfer also significantly inhibited T cell proliferation and secretion of the Thelper-1 cytokine interferon-gamma, increased the levels of the T helper- 2 cytokine interleukin-10, but had no effect on interleukin-4 and transforming growth factor-beta secretion. Therefore, calcitonin gene-related peptide gene transfer appears to ameliorate streptozotocin-induced diabetes through immune deviation.

The second peptide is named vasoactive intestinal peptide (VIP) and functions as a neuromodulator and neurotransmitter [54]. The peptide is a potent vasodilator that regulates smooth muscle activity, epithelial cell secretion, and blood flow in the gastrointestinal tract. Importantly, a body of evidence points to a significant role of vasoactive intestinal polypeptide in regulating immune responses. The peptide acts as a potent endogenous anti-inflammatory molecule and promotes the activity of $\mathrm{T}$ regulatory cells, which makes it a promising candidate for the treatments of inflammatory and autoim- 
mune diseases, such as septic shock, arthritis, multiple sclerosis, Crohn disease, and autoimmune diabetes [55, 56]. For example, a single intramuscular injection of 300 microgram of vasoactive intestinal polypeptide-encoding plasmid DNA significantly reduced the incidence of cyclophosphamide accelerated diabetes in female nonobese diabetic mice, from $70 \%$ in control to $30 \%$ on day 33 post delivery in 8 -10-week-old mice [57]. A subsequent report in a different model system indicated that injection of the peptide could activate $\mathrm{FoxP}^{+} \mathrm{CD} 4^{+} \mathrm{CD} 25^{\text {high }} \mathrm{T}$ regulatory cells and protect against acute graft-versushost disease in a mouse model of allogeneic bone marrow transplantation [58].

\subsection{Summary of Section 2}

Section 1 covers plasmid DNA encoding small protein molecules like cytokines, chemokines, peptides and other immune cell-manipulating agents with therapeutic effects on preclinical type 1 diabetes (Table 1). These approaches belong to systemic treatments and inevitably bear the risks associated with nonspecific immune suppression and chronic complications resulting from interference with the host immune system. Nonetheless, if used as adjuvants or supplements to pancreatic autoantigen-targeting therapies like DNA vaccines, these approaches could be used selectively in DNA-based combination therapies. We provide examples of such approaches in Section 2 of this chapter.

\section{DNA vaccine immunotherapies}

Plasmid DNA vaccine-based immunotherapy is a promising therapeutic field for treatment of type 1 diabetes. Clinical proof of concept has already been provided with results from phase I/II trials where individuals with new-onset type 1 diabetes were treated with proinsulinencoding plasmid DNA [15]. Nevertheless, although beneficial effects were observed, it is clear that efficacy must be significantly improved. Improving efficacy will be likely dependent on the ability to modulate both the innate immune system, through activation of tolerogenic antigen-presenting cells like dendritic cells, and the adaptive immune system, through activation of various populations of regulatory cells. DNA vaccines are particularly well positioned to achieve this goal because plasmid DNA is information-based, and can encode molecules that affect the immune system in different manners. The challenge is to identify which combination of functions should be delivered together with a pancreatic autoantigen to treat disease with maximum efficacy and safety.

Several beta cell autoantigens have been tested in mice for induction of immune tolerance by DNA vaccines and will be discussed in this section. Immune mechanisms associated with the therapeutic effects of DNA vaccines can be complex because of the variety of cells that can process the information encoded by plasmid DNA. Regardless, the major goals are to induce diabetic suppressive dendritic cells, T regulatory lymphocytes, and the cell death and inactivation of $\mathrm{T}$ effector lymphocytes that destroy pancreatic beta cells. 


\begin{tabular}{|c|c|c|c|c|}
\hline Categories & Encoded Products & Immune Responses & Trials & References \\
\hline \multicolumn{5}{|l|}{ Gene Therapies } \\
\hline \multirow[t]{3}{*}{ Cytokines } & IL-4 & Thelper-2 & Preclinical & [18-21] \\
\hline & IL-10 & Thelper-2 & Preclinical & [22-26] \\
\hline & $\begin{array}{l}\text { IL-4 + IL-10 as } \\
\text { Nanoparticle }\end{array}$ & Thelper-2 & Preclinical & [27-29] \\
\hline \multirow[t]{2}{*}{ Chemokines } & C-C Motif Ligand 4 & Thelper-2, Tregs & Preclinical & {$[45]$} \\
\hline & C-X-C Motif Ligand 10 & Tregs & Preclinical & {$[42,43]$} \\
\hline Cellular & Galectin-9 & Thelper-2 & Preclinical & {$[48]$} \\
\hline \multirow[t]{4}{*}{ Manipulations } & Decoy Receptor 3 & Thelper-2, DCs & Preclinical & {$[50]$} \\
\hline & CD44 & Antibodies & Preclinical & [51] \\
\hline & CGRP & Thelper-2 & Preclinical & [53] \\
\hline & VIP & Tregs & Preclinical & [57] \\
\hline \multicolumn{5}{|l|}{ DNA Vaccines } \\
\hline & Insulin B chain & Thelper-2 & Preclinical & {$[60,67]$} \\
\hline & Insulin B Chain + IL-4 & Thelper-2 & Preclinical & [61] \\
\hline & Proinsulin + Anti-CD154 & CD25+ Tregs & Preclinical & {$[62]$} \\
\hline & Proinsulin DNA + Peptide & CD25-Tregs & Preclinical & [63] \\
\hline & Proinsulin + PRP III & CD25+ Tregs & Preclinical & {$[64]$} \\
\hline & Pre-proinsulin + B7-1wa & $?$ & Preclinical & [65] \\
\hline & Proinsulin & $?$ & $\begin{array}{l}\text { Preclinical, } \\
\text { Clinical }\end{array}$ & {$[15,66,68]$} \\
\hline & Proinsulin + Anti-CD3 & $\begin{array}{c}\text { Thelper-2, CD25+ } \\
\text { Tregs }\end{array}$ & Preclinical & [71] \\
\hline & HSP 60 & Thelper-2 & PreClinical & [79] \\
\hline & HSP 65 & Thelper-2, Tregs & Preclinical & {$[80,81]$} \\
\hline & Secreted GAD65, GAD65 & Thelper-2 & Preclinical & {$[84,85,88,92]$} \\
\hline & $\begin{array}{c}\text { GAD65-Ig FC + } \\
\text { IL-4/IL-10/IL-4 \& IL-10 }\end{array}$ & Thelper-2 & Preclinical & {$[86,87]$} \\
\hline & GAD65 + Anti-CD3 & Tregs & Preclinical & [94] \\
\hline & Secreted GAD65 + BAX & Tregs, DCs & Preclinical & [97-99] \\
\hline & $\mid A-2+I L-4$ & Tregs? & Preclinical & {$[101]$} \\
\hline & GPI + lysosome & nTregs & Preclinical & [102] \\
\hline
\end{tabular}

Table 1. Plasmid DNA Based Immunotherapies for Type 1 Diabetes. The table summarizes plasmid DNA based immunotherapies under two categories: Gene therapies and DNA vaccines. Immunotherapies are listed according to their category, type of immune response and trial. Abbreviation: IL, interleukin; CD, cluster of differentiation; PRPIII, pancreatic regenerating protein III; CGRP, calcitonin gene-related peptide; VIP, vasoactive intestinal polypeptide; HSP, heat shock protein; GAD, glutamic acid decarboxylase. IA, insulinoma associated protein; Tregs, T regulatory cells; DCs: dendritic cells. 


\subsection{Insulin DNA vaccines}

Thus far, the only DNA vaccine that has been tested in both preclinical and clinical trials is a plasmid DNA construct coding for intracellular proinsulin, which is a partially processed nonfunctional form of insulin. Insulin is not only the hormone produced by beta-cells that controls carbohydrate and fat metabolism in the body, it is also a main target autoantigen in autoimmune diabetes and the presence of anti-insulin autoantibodies can be an indication of disease initiation [59]. DNA vaccines coding for different forms of insulin have been investigated for type 1 diabetes immunotherapy since the late 1990's. The first report to demonstrate efficacy used a virus-induced diabetic mouse model system, and showed that intramuscular injection of plasmid DNA encoding the insulin B chain reduces the incidence of diabetes (blood glucose $>350 \mathrm{mg} / \mathrm{dL}$ ) from $100 \%$ down to $50 \%$ [60]. The DNA vaccine induced insulin B-chain specific $\mathrm{CD}^{+} \mathrm{T}$ regulatory cells that secreted interleukin- 4 , and locally reduced autoreactive activity of cytotoxic T lymphocytes in the pancreatic draining lymph nodes. Further work showed that co-delivery of interleukin- 4 was required to prevent diabetes onset in male nonobese diabetic mice [61].

Two isoforms of insulin are synthesized in rodent animals, insulin I in islets and insulin II in both islets and thymus while humans have only one form of insulin. The pancreatic beta cells synthesize proinsulin before converting it to functional insulin. In that regard, intranasal delivery of plasmid DNA encoding mouse proinsulin II together with injection of an antiCD154 (also named CD40 ligand) antibody to prevent T cell activation was reported to prevent type 1 diabetes in nonobese diabetic mice [62]. Delivery of 300 microgram DNA and 50 microgram antibody over a 2-week interval at 4 weeks of age synergistically prevented diabetes, reducing disease incidence from $100 \%$ diabetic down to $0 \%$ in 40 -week old mice. Injection of the anti-CD154 antibody alone reduced the incidence to $50 \%$. However, delivery of the DNA vaccine alone did not reduce diabetes incidence, even though it could induce $\mathrm{T}$ regulatory cells and reduce insulitis.

Another report has shown that co-delivery of 50 microgram plasmid DNA encoding human proinsulin together with 100 microgram insulin peptide twice over a 2-week interval could prevent diabetes until 24 weeks of age in 6 week old nonobese diabetic mice. In contrast, DNA or peptide alone did not prevent disease [63]. Results also indicated induction of CD4 ${ }^{+} \mathrm{CD} 25$ islet specific $\mathrm{T}$ regulatory cells producing transforming growth factor-beta only in the coimmunization group.

In another study, a DNA vaccine encoding proinsulin and pancreatic regenerating (Reg) III protein resulted in a significant reduction of hyperglycemia and diabetes incidence with increased serum insulin in a streptozotocin- induced mice model [64]. The treatment also restored the balance of $\mathrm{T}$ helper- $1 / \mathrm{T}$ helper- 2 cytokines, expanded $\mathrm{CD} 4{ }^{+} \mathrm{CD} 25^{+} \mathrm{Foxp} 3^{+} \mathrm{T}$ regulatory cells, and attenuated insulitis by inhibiting activation of nuclear factor-kappa B (NF$\kappa \mathrm{B})$ in the pancreas, which is thought to promote the regeneration of islet beta cells.

Cytotoxic T lymphocyte antigen 4 (CTLA-4 or CD152) is a strong negative regulator of T cell activity and another example of an immunomodulator that can be co-delivered with an autoantigen. Like CD28 (a positive regulator), CTLA-4 binds to B7-1 and B7-2. It was found 
that a single amino acid substitution in B7-1 (denoted B7-1wa) could abrogate specific binding to CD28 but not to CTLA-4. Co-delivery of B7-1wa and preproinsulin I encoded by plasmid DNA abrogated reactivity to insulin and ameliorated type 1 diabetes in nonobese diabetic mice, although delivery of either preproinsulin I or B7-1wa alone did not suppress the disease [65]. Interferon-gamma and interleukin- 4 were both depressed, arguing against a T helper- 2 bias, but reactivity to glutamic acid decarboxylase 65 was not altered. Suppressor cells were not identified, suggesting induction of tolerance to insulin by either $\mathrm{T}$ cell anergy or deletion in this model.

Among the most promising reports of insulin DNA vaccination is a plasmid DNA construct encoding mouse proinsulin II that could reduce the incidence of diabetes in nonobese diabetic mice when administered intramuscularly to prediabetic 8-week old mice (prophylactic setting), and to diabetic mice older than 12-week (therapeutic setting) with blood glucose $>170$ $\mathrm{mg} / \mathrm{dL}[66,67]$. The efficacy of the vaccine was improved by increasing the level of expression of insulin, frequency of dosing, dosage, and subcelullar localization modification of the autoantigen to the intracellular compartment instead of being secreted. In the prophylactic setting, 8 weekly injections of 50 microgram of the DNA vaccine decreased the incidence of diabetes from $80 \%$ in the control group down to $45 \%$ in 25 -week old mice. The treatment caused increased numbers of interferon-gamma secreting cells and a decrease in insulin autoantibodies. In the therapeutic setting, the DNA vaccine reduced diabetes from $100 \%$ in the control groups down to $25 \%$ in treated mice 25 weeks post treatment initiation. The treatment induced increased numbers of insulin-specific interferon-gamma-producing $\mathrm{T}$ cells and levels of interleukin-10, which suggested the possible induction of T regulatory-1 cells. Adoptive transfer experiments indicated that the protection was not mediated by the induction of $\mathrm{CD} 4{ }^{+} \mathrm{CD} 25^{+} \mathrm{T}$ regulatory cells.

Most important, a similar DNA vaccine encoding human proinsulin was used in phase I/II clinical trials and has been the only human trial of a DNA vaccine for diabetes conducted to date $[68,69]$. Construct BHT-3021 was delivered intramuscularly using four doses of plasmid DNA, i.e., 0.3, 1, 3 and 6 milligram, administered once a week for 12 weeks. The interim results for the 1 milligram dose showed pancreatic beta-cell preservation, demonstrated by a mean $17 \%$ increase in C-peptide levels with BHT-3021 by week 15 after enrollment, whereas placebo patients experienced a mean $42 \%$ decrease in C-peptide. Evidence for immune tolerance was suggested by a mean $17 \%$ reduction in anti-insulin antibodies, and $25 \%$ reduction in antiglutamic acid decarboxylase 65 antibodies by week 15 after enrollment, whereas placebo patients experienced a mean $6 \%$ and $4 \%$ increase, respectively. The most recent report of the trial claimed that BHT-3021 could preserve C-peptide levels for at least six months and one year in some of the patients from the point of initiation of the therapy [15]. These results together with its favorable side-effects profile appear to be somewhat comparable to those reported with anti-CD3 monoclonal antibody, and the glutamic acid decarboxylase 65 protein vaccines for type 1 diabetes.

However, thus far, no immunotherapy alone has been reported to cause long term remission of clinical type 1 diabetes. This was confirmed with the announcements in 2011 of the failure of three phase III clinical trials for type 1 diabetes that tested two anti-CD3 monoclonal 
antibodies and a GAD65 protein vaccine. The need to increase therapeutic efficacy has generated an increased interest in combination immunotherapies [70-72]. Indeed, it is reasonable to anticipate that a variety of synergistic and additive effects may be induced by combining different agents. For example, combination treatment with anti-CD3 epsilon specific antibody and intranasal delivery of proinsulin peptide could reverse recent onset diabetes in nonobese diabetic mice as well as in a virus-induced diabetic mouse model with much higher efficacy than monotherapy using anti-CD3 or peptide alone [71]. Protection was associated with expansion of $\mathrm{CD}_{2} 5^{+}$Foxp $^{+}$and insulin specific $\mathrm{T}$ regulatory cells producing protective cytokines, such as interleukin-10, transforming growth factor-beta, and interleukin-4. In addition, these cells can transfer dominant tolerance to recent onset diabetic recipients, and suppress heterologous autoaggressive CD8 T cell responses. While animal studies do provide a rationale for combining therapies, there are hurdles that still need to be overcome for translation to the clinic. For example, the possibility of unforeseen drug interactions is not in the interest of pharmaceutical and biotech companies and could stop them from evaluating their drugs in combination trials [72].

\subsection{Heat shock protein $60 / 65$ DNA vaccines}

Heat shock protein 60 (HSP60) is a 60-kilodalton mammalian protein that promotes the proper folding of mitochondrial proteins and a possible autoantigen in type 1 diabetic children and murine models [73, 74]. Epitope scanning of heat shock protein 60 with antibodies identified peptide DiaPep277 with the amino sequence VLGGGVALLRVIPALDSLTPANED as an immunodominant epitope in type 1 diabetic child patients $[75,76]$. From an immunological standpoint, mammalian heat shock proteins can also act as damage-associated molecular patterns that are released or presented by dying cells and can activate antigen-presenting cells of the innate immune system [77]. Heat shock proteins activate macrophages and dendritic cells through Toll-like receptor 4, which belongs to a class of membrane-bound proteins that act as sensors for immune cell activation, and promote proinflammatory effector immune responses. Paradoxically, heat shock proteins can also mediate anti-inflammatory response through Toll-like receptor 2 on T cells, and DiaPep277 peptide functions through a Toll-like receptor 2-mediated mechanism [78].

Plasmid DNA coding for heat shock protein 60 has been shown to prevent type 1 diabetes in mice. For example, two times 100 microgram intramuscular injections of plasmid DNA coding for mammalian heat shock protein 60 into 4-week old nonobese diabetic mice suppressed cyclophosphamide-accelerated diabetes, with $30 \%$ of treated mice developing diabetes compared with $60 \%$ in vector treated controls [79]. Disease prevention was associated with reduced $\mathrm{T}$ cell proliferation, increased in interleukin-10 and interleukin-5 secretion, and decreased interferon-gamma secretion, which suggested a shift from a Thelper-1 like toward a T helper-2 like immune response.

In addition, plasmid DNA encoding mycobacterial 65-kilodalton heat shock protein could also affect diabetes by causing decreased insulitis when injected intramuscularly in three doses (100 microgram each) at 2-week intervals into 6- to 8-week-old, streptozotocin-induced diabetic C57BL/6 mice [80]. The treatment was associated with the appearance of a regulatory 
cell population in the spleen, with higher production of interleukin-10 in the spleen and islets, and with a decreased infiltration of CD8 T lymphocytes in the islets. The same DNA vaccine with the same dose and delivery reduced the occurrence of diabetes from $100 \%$ to $33 \%$ in 28 week old nonobese diabetic mice when injected at 4-week of age, and was associated with a reduction in CD4 and CD8 T cells infiltration, appearance of CD25 cells, and increased levels of interleukin-10 in pancreatic islets [81].

\subsection{Glutamic acid decarboxylase DNA vaccines}

Glutamic acid decarboxylase 65 is an enzyme that catalyzes the synthesis of gamma-aminobutyric acid (GABA) which acts as a neuroinhibitor as well as an immunoregulatory molecule. Evidence indicates that glutamic acid decarboxylase 65 may have a critical early role in mediating islet beta cell destruction and is an important target autoantigen in type 1 diabetes. Detection of anti-glutamic acid decarboxylase antibodies in the sera of prediabetic patients is a reliable predictive marker for the progression to overt diabetes, and anti-glutamic acid decarboxylase reactivity can be detected in nonobese diabetic mice model early in the disease process $[82,83]$.

Plasmid DNA vaccines coding for glutamic acid decarboxylase 65 are currently at the preclinical stage. The first report of a beneficial effect in nonobese diabetic mice showed that plasmid DNA encoding wild-type intracellular or engineered secreted glutamic acid decarboxylase, i.e., a fusion of the interleukin-2 signal peptide with a truncated form of human glutamic acid decarboxylase 65, caused decreased insulitis compared to plasmid vector alone when delivered intramuscularly, and was accompanied by elevated secretion of interleukin- 4 by splenocytes [84]. A subsequent report indicated that only the DNA vaccine encoding secreted glutamic acid decarboxylase could suppress cyclophosphamide-accelerated diabetes in 4week old female nonobese diabetic mice with a tendency to increase T helper-2 like activity when two times 400 microgram were delivered intramuscularly over 3 days [85].

A report published the same year corroborated the notion that secretion of glutamic acid decarboxylase encoded by a DNA vaccine is important to ameliorate diabetes in mice [86]. In this report, plasmid DNA was engineered to encode a secreted fusion protein of a truncated form of glutamic acid decarboxylase 65 and an IgG Fc fragment as well as interleukin-4. Intramuscular injection of 50 microgram of the vaccine effectively prevented diabetes in nonobese diabetic mice treated at early (4-week old, 3 times weekly) or late (12-week old, 4 times weekly) preclinical stages of diabetes. Diabetic onset reduction went from $75 \%$ in controls to $25 \%$ in treated animals at week 50 . Protection was dependent on interleukin-4 as well as endogenous interleukin-4, and associated with the induction of glutamic acid decarboxylase 65 specific regulatory Thelper-2 cells [87]. In addition, the same strategy was used with insulin as the target autoantigen. In this case, the DNA vaccine encoding an insulin B chain/IgG Fc fusion protein and interleukin- 4 caused accelerated progression of insulitis and diabetes, which correlated with increased numbers of interferon-gamma secreting $\mathrm{T}$ cells in response to insulin B chain specific peptides. On the other hand, a group reported that a DNA vaccine encoding full-length intracellular human glutamic acid decarboxylase 65 alone could prevent spontaneous diabetes in nonobese diabetic mice when delivered at 4 or 10 weeks of age using 
intramuscular injections of two times 50 microgram DNA [88]. Notably, disease prevention was associated with CD28/B7 costimulation because co-expression of B7-1 or B7-2 and glutamic acid decarboxylase 65 by the same DNA vaccine abrogated protection. Another study investigated the relationship between endogenous expression levels of glutamic acid decarboxylase in beta-cells and the efficacy of DNA vaccination [89]. Injection of plasmid DNA coding for glutamic acid decarboxylase into mice with lower expression levels of the autoantigen resulted in the induction of autosuppressive regulatory cells characterized by increased interleukin-4 production (T helper-2 like). In contrast, higher levels of the autoantigen favored $\mathrm{T}$ helper-1-like autoaggressive responses characterized by increased the interferon-gamma generation. Immunization with a DNA vaccine coding the glutamic acid decarboxylase and interleukin-4 reduced the risk of augmenting autoaggression and thus increased the safety of this immune-based therapy.

DNA vaccines encoding secreted glutamic acid decarboxylase combined with anti-inflammatory interleukins have also been applied to pancreatic transplant for type 1 diabetes. Survival of syngeneic neonatal pancreata transplanted under the kidney capsule of nonobese diabetic mice was promoted by intramuscular injection of a DNA vaccine encoding the secreted glutamic acid decarboxylase 65/IgG Fc fusion and interleukin-4 plus interleukin-10 [90]. The treatment consisted of 50 microgram of the vaccine delivered weekly for four weeks from the age of 10 weeks with transplantation performed one week after the final DNA vaccination. DNA vaccination protected syngeneic islet in transplanted mice, with $100 \%$ diabetic mice in controls compared to $20 \%$ diabetes incidence in treated animals at 30 weeks of age and 15 weeks post transplant. Increased islet survival required co-delivery of both interleukin- 4 and interleukin-10 and correlated with a marked reduction in interferon-gamma reactivity as well as an increase in interleukin-10 secreting $\mathrm{T}$ cells. These results made apparent the increased difficulty in protecting exogenous syngeneic islet and the need for more stringent conditions of vaccination in the transplantation setting.

Most DNA vaccines for type 1 diabetes have been delivered into muscle tissue. The main rationale for using this route of delivery is that it permits administration of larger amounts of DNA, but other routes may be more advantageous to induce tolerogenic responses. In that regard, a report compared intramuscular, intradermal, and oral delivery of plasmid DNA coding for the intracellular or secreted form of glutamic acid decarboxylase for prevention of diabetes in 4-week-old nonobese diabetic mice [91]. Results indicated that both intradermal and oral deliveries were more effective than intramuscular delivery for delaying the disease. Cytokine-specific ELISpot analysis indicated that immune responses induced by the DNA vaccination were generally more dependent on the cellular localization of glutamic acid decarboxylase antigen than on the delivery route, although ELISA indicated that intradermal delivery of DNA is most likely to induce a T helper-2 like response.

In addition to route of delivery, the method used to administer a DNA vaccine can be beneficial by increasing efficacy of DNA uptake and improving immune responses. For example, dermal delivery of plasmid DNA using gene gun technology, which consists in shooting gold microparticles covered with DNA, can improve protection from diabetes. In this regard, gene-gun delivery of 1 microgram of a DNA vaccine encoding the secreted glutamic acid decarboxylase 
65/IgG Fc fusion polypeptide into 10-week old nonobese diabetic mice was compared with intramuscular injection of 50 microgram of the same vaccine [92]. Results indicated that, in both cases, gene expression peaked at week 8 post deliveries and was maintained until at least week 35 with more than $40 \%$ higher expression from the gene-gun delivery. However, only gene-gun delivery protected mice from diabetes with $90 \%$ diabetic animals in controls down to $50 \%$ diabetic mice at 35 weeks of age. In contrast, gene-gun administration of plasmid DNA encoding intracellular glutamic acid decarboxylase 65 to 3-week old nonobese diabetic mice did not suppress diabetes in nonobese diabetic mice [93]. The different results might be attributed to the different subcellular localizations of the autoantigen.

As mentioned earlier, combination therapy is being increasingly considered as a means to improve efficacy of immunotherapy for type 1 diabetes. Combining a DNA vaccine coding for intracellular GAD65 with an anti-CD3 monoclonal antibody has been investigated in two different mouse model systems for that purpose [94]. Results indicated that successful treatment was observed in a virus-induced diabetic model (the RIP-LCMV-GP model) but not the nonobese diabetic mouse. Efficacy was associated with an expansion of bystander suppressor T regulatory cells recognizing the C-terminal region of GAD65 and secreting interleukin-10, transforming growth factor-beta and interferon-gamma. These results also showed that efficacy was associated with numbers of antigen-specific T cells available at time of treatment, which was different beween the two animal models. The findings hold important implications to predict the success of antigen-based clinical trials where responsiveness to immunotherapy may vary from patient to patient.

Thus far, we have described in this section how DNA vaccines can be engineered to enhance tolerogenic-like immune responses by co-delivering cytokine-encoding DNA, an antibody, engineering subcellular localization of a target autoantigen, and choosing an effective route and method of delivery. These results obtained by different laboratories illustrate the promising potential of DNA vaccination as a safe, low-cost and patient-friendly means to treat autoimmune diabetes and other immune-mediated inflammatory disorders. Yet, as with all immunotherapies that seek means of improving the life of diabetic individuals, there is a pressing need to improve treatment efficacy through the identification of novel molecular adjuvants for the safe induction of immune tolerance.

Ideally, these adjuvants should attempt to mimic how immune tolerance is maintained in steady state. Here, we briefly discuss plasmid-induced apoptosis as a possible means to mimic physiological immune tolerance and to approach the "Holy Grail" of immunotherapy, namely, the ability to suppress inflammation in a homeostatic manner. Apoptosis is a constantly ongoing form of cell death that produces fifty to seventy billion dead cells on a daily basis in an average human adult [95]. Upon a given intrinsic or extrinsic signal, cells initiate the process of apoptosis and become membrane-bound cellular fragments, or apoptotic bodies, which are rapidly engulfed and processed by surrounding living cells. For many years, it was believed that these apoptotic bodies had little effect on the immune system. Today, it has become clear that apoptosis is an important physiological means to establish and maintain immune tolerance in peripheral tissues. Apoptotic cells play a fundamental role as they not only serve as a source of self-antigens, but also recruit antigen-presenting cells, secrete anti-inflammatory 
cytokines, and display tolerogenic molecules [96]. The remarkable capacity of apoptotic cells to induce either tolerogenic immune responses or immunogenic responses depending on signals received makes them attractive candidates to intervene in many disorders like infectious diseases, cancer, and autoimmune diseases.

The first report of DNA vaccines designed for pro-apoptotic immunoregulation, i.e., antiinflammatory, used plasmid DNA coding for the pro-apoptotic BAX protein and intracellular or secreted glutamic acid decarboxylase, to prevent diabetes in the nonobese diabetic mouse [97]. Results indicated that intramuscular injection of the BAX cDNA recruited dendritic cells carrying vaccine-encoded protein in both spleen and lymph nodes. Furthermore, delivery of two times 150 microgram plasmid DNA coding for secreted glutamic acid decarboxylase and BAX at 3 days interval into 4-week old mice prevented diabetes, i.e, reduced the incidence from $93 \%$ in controls down to $47 \%$ in treated animals. In contrast, the vaccines coding for BAX DNA alone or intracellular glutamic acid decarboxylase and BAX did not prevent diabetes. Notably, ELISA results suggested that co-delivery of BAX suppressed T helper-2 like activity, which indicated that another cell type was responsible for disease suppression. Indeed, a subsequent report showed that delivery of both secreted glutamic acid decarboxylase and $\mathrm{BAX}$ were required to induce $\mathrm{CD} 4^{+} \mathrm{CD} 25^{+} \mathrm{FoxP} 3^{+}$ cells with contact dependent regulatory activity [98].

Importantly, additional studies revealed that increased CpG methylation of plasmid DNA together with delivery of secreted glutamic acid decarboxylase and BAX DNA could act synergistically to ameliorate recent onset diabetes in nonobese diabetic mice [99]. A weekly intradermal injection of 50 microgram of the vaccine over eight weeks following early hyperglycemia ameliorated diabetes at 40 weeks of age, from $90 \%$ diabetic mice in controls down to $20 \%$ in treated mice. Remarkably, DNA hypermethylation caused increased numbers of tolerogenic-like plasmacytoid dendritic cells in lymph nodes. It is hypothesized that increased CpG methylation of plasmid DNA makes the DNA vaccine appear more mammalian-like to the immune system, as it is known that bacterial DNA has low levels of CpG methylation that can act as an inflammatory signal [100]. Taken together these results indicate that apoptosis-inducing DNA vaccination is a promising approach for treatment of type 1 diabetes.

\subsection{Other DNA vaccines}

DNA vaccines encoding less studied autoantigens have also been investigated. For example, insulinoma-associated protein 2 (IA-2), which is expressed in islets, brain, and neuro-endocrine cells, is a member of the protein tyrosine phosphatase family and targeted by autoimmune $\mathrm{T}$ cells in type 1 diabetes. A DNA vaccine encoding insulinoma-associated protein 2 with or without the combination of DNA coding for interleukin-4 and monocyte chemoattractant protein-1 (MCP-1) was injected intramuscularly into pre-diabetic non-obese diabetic mice using 3 x 100 microgram DNA delivered over four weeks [101]. The treatment could protect mice from diabetes, from $60 \%$ in controls to $10-20 \%$ diabetic animals at 30 weeks of age. There was no difference in efficacy between groups treated with the DNA vaccine alone or combined 
with interleukin 4/MCP1, and animals in both groups had fewer CD8 T lymphocyte counts in spleen.

In another example, a DNA vaccine treatment strategy was designed to target an antigenic peptide (glucose-6-phosphate isomerase, GPI) to the lysosomal compartment. A specific T cell population termed $2.5 \mathrm{mi}^{+} \mathrm{T}$ cells is known to share reactivity with the diabetogenic $\mathrm{T}$ cell clone BDC-2.5 in the NOD mouse [102]. Lysosome targeting of single peptide epitope was sufficient to induce protection against type 1 diabetes which was not the result of antigen-specific $\mathrm{T}$ cell anergy. Typical T helper- 2 cytokines like interleukin-10 or -4 were undetectable in $2.5 \mathrm{mi}^{+} \mathrm{T}$ cells, arguing against a mechanism of immune deviation. Instead, the expanded $2.5 \mathrm{mi}^{+} \mathrm{T}$ cell population produced interferon-gamma similar to $2.5 \mathrm{mi}^{+} \mathrm{T}$ cells from naive mice. Protection against diabetes induced by DNA vaccination was completely lost in NOD.CD28 ${ }^{-/}$mice, which are largely deficient of natural $\mathrm{T}$ regulatory cells. Furthermore, diabetes onset was delayed in $\mathrm{T}$ regulatory-reconstituted and DNA-treated NOD.SCID mice, although antigen-specific Foxp $3^{+}$cells did not expand in response to DNA treatment. These findings indicated a T regulatory-mediated protective mechanism that was independent of the expansion or de novo generation of antigen-specific T regulatory cells.

\subsection{Summary of section 3}

DNA vaccination has been tested in clinical trials for treatment of new-onset type 1 diabetes with encouraging results, but efficacy must be improved. The number and variety of strategies that have been developed to improve efficacy of DNA vaccination for autoimmune diabetes is a testament to the flexibility and potential of DNA vaccine immunotherapy.

\section{Conclusion: Plasmid DNA as a promising immunotherapy for Type 1 diabetes}

Plasmid DNA is a versatile vector platform permitting the seamless integration of different immune modulators into a product that can be manufactured in a generic manner. As we have seen in this chapter, plasmid DNA has been extensively investigated for the prevention and treatment of type 1 diabetes in different animal model systems. Plasmid DNA-based gene immunotherapies do not encode an autoantigen and act systemically to different degrees, which could result in serious adverse events if used over time. Nevertheless, gene immunotherapies could still be utilized as molecular adjuvants with DNA vaccines that target pancreatic beta cell autoantigens. It is possible that different stages during progression of disease will require different therapeutic agents or combinations thereof according to immune responses to therapy. It is also anticipated that some strategies will be safer and more robust than others, but there is unfortunately no animal model that can predict successful bench-tobedside translation of a given strategy. In that regard, immunological biomarkers and their pre-clinical and clinical correlates will be needed to determine which strategies are most likely to be effective in humans, and to what extent different immunotherapies might be combined. Combinatorial therapies include co-delivery of DNA vaccines with gene therapy, peptide 
vaccines, monoclonal antibodies, and other adjuvant agents that have shown synergistic effects. In one possible scenario, autoantigen-specific immunotherapies could be used over the long-term as stand-alone treatments, with the occasional help of systemic immune modulators depending on disease severity. Regardless of the strategy to be chosen, there is a strong case to be made for including plasmid DNA immunotherapy in future treatments of type 1 diabetes.

\section{Author details}

Alice $\mathrm{Li}^{1}$ and Alan Escher ${ }^{2}$

1 Loma Linda University, Loma Linda, California, USA

2 SEKRIS Biomedical Inc., Redlands, California, USA

\section{References}

[1] Stiller CR, Dupré J, Gent M, Jenner MR, Keown PA, Laupacis A, Martell R, Rodger NW, von Graffenried B, Wolfe BM. Effects of cyclosporine immunosuppression in insulin-dependent diabetes mellitus of recent onset. Science. 1984;223(4643):1362-7.

[2] Long SA, Rieck M, Sanda S, Bollyky JB, Samuels PL, Goland R, Ahmann A, Rabinovitch A, Aggarwal S, Phippard D, Turka LA, Ehlers MR, Bianchine PJ, Boyle KD, Adah SA, Bluestone JA, Buckner JH, Greenbaum CJ; Diabetes TrialNet and the Immune Tolerance Network. Rapamycin/IL-2 combination therapy in patients with type 1 diabetes augments Tregs yet transiently impairs $\beta$-cell function. Diabetes. 2012;61(9):2340-8.

[3] Kasi PM, Tawbi HA, Oddis CV, Kulkarni HS. Clinical review: Serious adverse events associated with the use of rituximab - a critical care perspective. Crit Care. 2012;16(4): 231.

[4] Lichtenstein GR, Feagan BG, Cohen RD, Salzberg BA, Diamond RH, Price S, Langholff W, Londhe A, Sandborn WJ. Serious infection and mortality in patients with Crohn's disease: more than 5 years of follow-up in the TREAT ${ }^{\text {TM }}$ registry. Am J Gastroenterol. 2012;107(9):1409-22.

[5] von Herrath MG, Harrison LC. Antigen-induced regulatory T cells in autoimmunity. Nat Rev Immunol. 2003;3(3):223-32.

[6] Liu Y, Huang H, Saxena A, Xiang J. Intratumoral coinjection of two adenoviral vectors expressing functional interleukin-18 and inducible protein-10, respectively, synergizes to facilitate regression of established tumors. Cancer Gene Ther. 2002;9(6): 533-42. 
[7] Pedotti R, Sanna M, Tsai M, DeVoss J, Steinman L, McDevitt H, Galli SJ. Severe anaphylactic reactions to glutamic acid decarboxylase (GAD) self peptides in NOD mice that spontaneously develop autoimmune type 1 diabetes mellitus. BMC Immunol. 2003;4:2.

[8] Tyagi RK, Garg NK, Sahu T. Vaccination Strategies against Malaria: novel carrier(s) more than a tour de force. J Control Release. 2012;162(1):242-54.

[9] Goldmann K, Ensminger SM, Spriewald BM. Oral gene application using chitosanDNA nanoparticles induces transferable tolerance. Clin Vaccine Immunol. 2012;19(11):1758-64.

[10] Gramzinski RA, Millan CL, Obaldia N, Hoffman SL, Davis HL. Immune response to a hepatitis B DNA vaccine in Aotus monkeys: a comparison of vaccine formulation, route, and method of administration. Mol Med. 1998;4(2):109-18.

[11] Hu H, Lu X, Tao L, Bai B, Zhang Z, Chen Y, Zheng F, Chen J, Chen Z, Wang H. Induction of specific immune responses by severe acute respiratory syndrome coronavirus spike DNA vaccine with or without interleukin-2 immunization using different vaccination routes in mice. Clin Vaccine Immunol. 2007;14(7):894-901.

[12] Ginsberg BA, Gallardo HF, Rasalan TS, Adamow M, Mu Z, Tandon S, Bewkes BB, Roman RA, Chapman PB, Schwartz GK, Carvajal RD, Panageas KS, Terzulli SL, Houghton AN, Yuan JD, Wolchok JD. Immunologic response to xenogeneic gp100 DNA in melanoma patients: comparison of particle-mediated epidermal delivery with intramuscular injection. Clin Cancer Res. 2010;16(15):4057-65.

[13] Culina S, Boitard C, Mallone R. Antigen-based immune therapeutics for type 1 diabetes: magic bullets or ordinary blanks? Clinical \& Developmental Immunology. 2011;2011:286248.

[14] Abdulhaqq SA, Weiner DB. DNA vaccines: developing new strategies to enhance immune responses. Immunology Reviews. 2008;42(1-3):219-32.

[15] Garren H. DNA vaccines for autoimmune diseases. Expert Review of Vaccines. 2009;8(9):1195-203.

[16] Siatskas C, Chan J, Field J, Murphy K, Nasa Z, Toh BH, Alderuccio F. Gene therapy strategies towards immune tolerance to treat the autoimmune diseases. Current Gene Therapy. 2006;6(1):45-58.

[17] Johnson MC, Wang B, Tisch R. Genetic vaccination for re-establishing T-cell tolerance in type 1 diabetes. Human Vaccine. 2011;7(1):27-36.

[18] Cameron MJ, Strathdee CA, Holmes KD, Arreaza GA, Dekaban GA, Delovitch TL. Biolistic-mediated interleukin 4 gene transfer prevents the onset of type 1 diabetes. Human Gene Therapy. 2000;11(12):1647-56. 
[19] Lee M, Koh JJ, Han SO, Ko KS, Ki SW. Prevention of autoimmune insulitis by delivery of interleukin- 4 plasmid using a soluble and biodegradable polymeric carrier. Pharmaceutical research. 2002;19(3):246-9.

[20] Hayashi T, Yasutomi Y, Hasegawa K, Sasaki Y, Onodera T. Interleukin-4-expressing plasmid DNA inhibits reovirus type-2-triggered autoimmune insulitis in DBA/1 J suckling mice. International Journal of Experimental Pathology. 2003;84(2):101-6.

[21] Horiki M, Yamato E, Noso S, Ikegami H, Ogihara T, Miyazaki J. High-level expression of interleukin-4 following electroporation-mediated gene transfer accelerates Type 1 diabetes in NOD mice. Journal of Autoimmunity. 2003;20(2):111-7.

[22] Nitta Y, Tashiro F, Tokui M, Shimada A, Takei I, Tabayashi K, Miyazaki J. Systemic delivery of interleukin 10 by intramuscular injection of expression plasmid DNA prevents autoimmune diabetes in nonobese diabetic mice. Human Gene Therapy. 1998;9(12):1701-7.

[23] Koh JJ, Ko KS, Lee M, Han S, Park JS, Kim SW. Degradable polymeric carrier for the delivery of IL-10 plasmid DNA to prevent autoimmune insulitis of NOD mice. Gene Therapy. 2000;7(24):2099-104.

[24] Zhang ZL, Shen SX, Lin B, Yu LY, Zhu LH, Wang WP, Luo FH, Guo LH. Intramuscular injection of interleukin-10 plasmid DNA prevented autoimmune diabetes in mice. Acta Pharmacologica Sinica. 2003;24(8):751-6.

[25] Lee M, Park H, Youn J, Oh ET, Ko K, Kim S, Park Y. Interleukin-10 plasmid construction and delivery for the prevention of type 1 diabetes. Annals of the New York Academy of Sciences. 2006;1079:313-9.

[26] Basarkar A, Singh J. Poly (lactide-co-glycolide)-polymethacrylate nanoparticles for intramuscular delivery of plasmid encoding interleukin-10 to prevent autoimmune diabetes in mice. Pharmaceutical research. 2009;26(1):72-81.

[27] Ko KS, Lee M, Koh JJ, Kim SW. Combined administration of plasmids encoding IL-4 and IL-10 prevents the development of autoimmune diabetes in nonobese diabetic mice. Molecular Therapy. 2001;4(4):313-6.

[28] Lee M, Ko KS, Oh S, Kim SW. Prevention of autoimmune insulitis by delivery of a chimeric plasmid encoding interleukin-4 and interleukin-10. Journal of controlled release. 2003;88(2):333-42.

[29] Mandke R, Singh J. Cationic nanomicelles for delivery of plasmids encoding interleukin- 4 and interleukin-10 for prevention of autoimmune diabetes in mice. Pharmaceutical research. 2012;29(3):883-97.

[30] Kovarik P, Sauer I, Schaljo B. Molecular mechanisms of the anti-inflammatory functions of interferons. Immunobiology. 2007;212(9-10):895-901. 
[31] Tokui, M., A. Shimada, O. Funae, H. Nomaguchi, H. Okamura, I. Takei, and T. Saruta. 1998. Recombinant IL-18 administration suppresses cyclophosphamide- induced diabetes in NOD mice. Diabetes 47:A9862.

[32] Rothe H, Hausmann A, Casteels K, Okamura H, Kurimoto M, Burkart V, Mathieu C, Kolb H. IL-18 inhibits diabetes development in nonobese diabetic mice by counterregulation of Th1-dependent destructive insulitis. J Immunol. 1999;163(3):1230-6.

[33] Oikawa Y, Shimada A, Kasuga A, Morimoto J, Osaki T, Tahara H, Miyazaki T, Tashiro F, Yamato E, Miyazaki J, Saruta T. Systemic administration of IL-18 promotes diabetes development in young nonobese diabetic mice. Journal of Immunology. 2003;171(11):5865-75.

[34] Hasegawa K, Hayashi T, Maeda K, Onodera T. Plasmid encoding interferon-gamma exacerbates reovirus type-2-induced diabetes in DBA/1 suckling mice. Journal of Comparative Pathology. 2002;127(2-3):203-7.

[35] Zhang J, Huang Z, Sun R, Tian Z, Wei H. IFN- $\gamma$ induced by IL-12 administration prevents diabetes by inhibiting pathogenic IL-17 production inNOD mice.J Autoimmun. $2012 ; 38(1): 20-8$.

[36] Laing KJ, Secombes CJ. Chemokines. Developmental and comparative immunology. 2004 May 3;28(5):443-60.

[37] Sallusto F, Lenig D, Mackay CR, Lanzavecchia A. Flexible programs of chemokine receptor expression on human polarized T helper 1 and 2 lymphocytes. Journal of Experimental Medicine. 1998;187(6):875-83.

[38] D'Ambrosio D, Iellem A, Bonecchi R, Mazzeo D, Sozzani S, Mantovani A, Sinigaglia F. Selective up-regulation of chemokine receptors CCR4 and CCR8 upon activation of polarized human type 2 Th cells. Journal of Immunology. 1998;161(10):5111-5.

[39] Shimada A, Morimoto J, Kodama K, Suzuki R, Oikawa Y, Funae O, Kasuga A, Saruta T, Narumi S. Elevated serum IP-10 levels observed in type 1 diabetes. Diabetes Care. 2001;24(3):510-5.

[40] Morimoto J, Yoneyama H, Shimada A, Shigihara T, Yamada S, Oikawa Y, Matsushima K, Saruta T, Narumi S. CXC chemokine ligand 10 neutralization suppresses the occurrence of diabetes in nonobese diabetic mice through enhanced beta cell proliferation without affecting insulitis. Journal of Immunology. 2004;173(11):7017-24.

[41] Christen U, McGavern DB, Luster AD, von Herrath MG, Oldstone MB. Among CXCR3 chemokines, IFN-gamma-inducible protein of $10 \mathrm{kDa}$ (CXC chemokine ligand (CXCL) 10) but not monokine induced by IFN-gamma (CXCL9) imprints a pattern for the subsequent development of autoimmune disease. Journal of Immunology. 2003;171(12):6838-45.

[42] Shigihara T, Shimada A, Oikawa Y, Yoneyama H, Kanazawa Y, Okubo Y, Matsushima K, Yamato E, Miyazaki J, Kasuga A, Saruta T, Narumi S. CXCL10 DNA vaccina- 
tion prevents spontaneous diabetes through enhanced beta cell proliferation in NOD mice. Journal of Immunology. 2005;175(12):8401-8.

[43] Oikawa Y, Shimada A, Yamada Y, Okubo Y, Katsuki T, Shigihara T, Miyazaki J, Narumi S, Itoh H. CXC chemokine ligand 10 DNA vaccination plus Complete Freund's Adjuvant reverses hyperglycemia in non-obese diabetic mice. Review Of Diabetic Studies. 2010;7(3):209-24.

[44] Cameron MJ, Arreaza GA, Grattan M, Meagher C, Sharif S, Burdick MD, Strieter RM, Cook DN, Delovitch TL. Differential expression of CC chemokines and the CCR5 receptor in the pancreas is associated with progression to type I diabetes. Journal of Immunology. 2000;165(2):1102-10.

[45] Meagher C, Arreaza G, Peters A, Strathdee CA, Gilbert PA, Mi QS, Santamaria P, Dekaban GA, Delovitch TL. CCL4 protects from type 1 diabetes by altering islet betacell-targeted inflammatory responses. Diabetes. 2007;56(3):809-17.

[46] Sgouroudis E, Piccirillo CA. Control of type 1 diabetes by CD4+Foxp3+ regulatory T cells: lessons from mouse models and implications for human disease. Diabetes/ Metabolism Research and Reviews. 2009;25(3):208-18.

[47] Luczyński W, Stasiak-Barmuta A, Urban R, Urban M, Florys B, Hryszko M. Lower percentages of $\mathrm{T}$ regulatory cells in children with type 1 diabetes - preliminary report. Pediatric endocrinology, diabetes, and metabolism. 2009;15(1):34-8.

[48] Chou FC, Shieh SJ, Sytwu HK. Attenuation of Th1 response through galectin-9 and $\mathrm{T}$-cell Ig mucin 3 interaction inhibits autoimmune diabetes in NOD mice. European journal of immunology. 2009;39(9):2403-11.

[49] Sung HH, Juang JH, Lin YC, Kuo CH, Hung JT, Chen A, Chang DM, Chang SY, Hsieh SL, Sytwu HK. Transgenic expression of decoy receptor 3 protects islets from spontaneous and chemical-induced autoimmune destruction in nonobese diabetic mice. Journal of Experimental Medicine. 2004;199(8):1143-51.

[50] Wang YL, Chou FC, Sung HH, Fan PL, Hsueh CW, Lin WC, Chen SJ, Lin WW, Sytwu HK. Decoy receptor 3 protects non-obese diabetic mice from autoimmune diabetes by regulating dendritic cell maturation and function. Molecular Immunology. 2010;47(16):2552-62.

[51] Weiss L, Botero-Anug AM, Hand C, Slavin S, Naor D. CD44 gene vaccination for insulin-dependent diabetes mellitus in non-obese diabetic mice. Israel Medical Association Journal. 2008;10(1):20-5.

[52] Donato J. The Central Nervous System As A Promising Target To Treat Diabetes Mellitus. Curr Top Med Chem. 2012 Nov 12. [Epub ahead of print]

[53] Sun W, Wang L, Zhang Z, Chen M, Wang X. Intramuscular transfer of naked calcitonin gene-related peptide gene prevents autoimmune diabetes induced by multiple 
low-dose streptozotocin in C57BL mice. European Journal Of Immunology. 2003;33(1):233-42.

[54] Fahrenkrug J, Emson PC. Vasoactive intestinal polypeptide: functional aspects. Br Med Bull. 1982;38(3):265-70.

[55] Delgado M, Abad C, Martinez C, Juarranz MG, Arranz A, Gomariz RP, Leceta J. Vasoactive intestinal peptide in the immune system: potential therapeutic role in inflammatory and autoimmune diseases. Journal of molecular medicine. 2002;80(1):16-24.

[56] Pozo D, Delgado M. The many faces of VIP in neuroimmunology: a cytokine rather a neuropeptide? Federation of American Societies for Experimental Biology. 2004;18(12):1325-34.

[57] Herrera JL, Fernández-Montesinos R, González-Rey E, Delgado M, Pozo D. Protective role for plasmid DNA-mediated VIP gene transfer in non-obese diabetic mice. Annals of the New York Academy of Sciences. 2006;1070:337-41.

[58] Pozo D, Anderson P, Gonzalez-Rey E. Induction of alloantigen-specific human T regulatory cells by vasoactive intestinal peptide. Journal of Immunology. 2009;183(7): 4346-59.

[59] Bluestone JA, Herold K, Eisenbarth G. Genetics, pathogenesis and clinical interventions in type 1 diabetes. Nature. 2010;464(7293):1293-300.

[60] Coon B, An LL, Whitton JL, von Herrath MG. DNA immunization to prevent autoimmune diabetes. Journal of Clinical Investigation. 1999;104(2):189-94.

[61] Bot A, Smith D, Bot S, Hughes A, Wolfe T, Wang L, Woods C, von Herrath M. Plasmid vaccination with insulin $B$ chain prevents autoimmune diabetes in nonobese diabetic mice. Journal of immunology. 2001;167(5):2950-5.

[62] Every AL, Kramer DR, Mannering SI, Lew AM, Harrison LC. Intranasal vaccination with proinsulin DNA induces regulatory CD4+ T cells that prevent experimental autoimmune diabetes. J Immunol. 2006;176(8):4608-15.

[63] Zhang W, Jin H, Hu Y, Yu Y, Li X, Ding Z, Kang Y, Wang B. Protective response against type 1 diabetes in nonobese diabetic mice after coimmunization with insulin and DNA encoding proinsulin. Human Gene Therapy. 2010;21(2):171-8.

[64] Hou WR, Xie SN, Wang HJ, Su YY, Lu JL, Li LL, Zhang SS, Xiang M. Intramuscular delivery of a naked DNA plasmid encoding proinsulin and pancreatic regenerating III protein ameliorates type 1 diabetes mellitus. Pharmaceutical Research. 2011;63(4): 320-7.

[65] Prud'homme GJ, Chang Y, Li X. Immunoinhibitory DNA vaccine protects against autoimmune diabetes through cDNA encoding a selective CTLA-4 (CD152) ligand. Hum Gene Ther. 2002;13(3):395-406.

[66] Solvason N, Lou YP, Peters W, Evans E, Martinez J, Ramirez U, Ocampo A, Yun R, Ahmad S, Liu E, Yu L, Eisenbarth G, Leviten M, Steinman L, Garren H. Improved 
efficacy of a tolerizing DNA vaccine for reversal of hyperglycemia through enhancement of gene expression and localization to intracellular sites. Journal of Immunology. 2008;181(12):8298-307.

[67] Urbanek-Ruiz I, Ruiz PJ, Paragas V, Garren H, Steinman L, Fathman CG. Immunization with DNA encoding an immunodominant peptide of insulin prevents diabetes in NOD mice. Clin Immunol. 2001;100(2):164-71.

[68] Gottlieb P, Eisenbarth G, Kipnes M, Ratner R, Rockell J, Wagner R, Solvason N, Tersini K, Valone F, Woody K, Steinman L, Garren H. Interim Results of a Phase I/II Clinical Trial of a DNA Plasmid Vaccine (BHT-3021) for Type 1 Diabetes. 2008. URL: http://www.bayhilltx.com/abstracts.html

[69] Li L, Yi Z, Tisch R, Wang B. Immunotherapy of type 1 diabetes. Archivum Immunologiae et Therapiae Experimentalis. 2008;56(4):227-36.

[70] Luo X, Herold KC, Miller SD. Immunotherapy of type 1 diabetes: where are we and where should we be going? Immunity. 2010;32(4):488-99.

[71] Bresson D, Togher L, Rodrigo E, Chen Y, Bluestone JA, Herold KC, and von Herrath M. Anti-CD3 and nasal proinsulin combination therapy enhances remission from recent-onset autoimmune diabetes by inducing Tregs. Journal of Clinical Investigation. 2006;116(5):1371-81.

[72] Matthews JB, Staeva TP, Bernstein PL, Peakman M, von Herrath M; ITN-JDRF Type 1 Diabetes Combination Therapy Assessment Group. Developing combination immunotherapies for type 1 diabetes: recommendations from the ITN-JDRF Type 1 Diabetes Combination Therapy Assessment Group. Clin Exp Immunol. 2010;160(2): 176-84.

[73] Birk OS, Elias D, Weiss AS, Rosen A, van-der Zee R, Walker MD, Cohen IR. NOD mouse diabetes: the ubiquitous mouse hsp60 is a beta-cell target antigen of autoimmune T cells. J Autoimmun. 1996;9(2):159-66.

[74] Horváth L, Cervenak L, Oroszlán M, Prohászka Z, Uray K, Hudecz F, Baranyi E, Madácsy L, Singh M, Romics L, Füst G, Pánczél P. Antibodies against different epitopes of heat-shock protein 60 in children with type 1 diabetes mellitus. Immunology Letters. 2002;80(3):155-62.

[75] Eldor R, Kassem S, Raz I. Immune modulation in type 1 diabetes mellitus using DiaPep277: a short review and update of recent clinical trial results. Diabetes/Metabolism Research and Reviews. 2009;25(4):316-20.

[76] Fischer B, Elias D, Bretzel RG, Linn T. Immunomodulation with heat shock protein DiaPep277 to preserve beta cell function in type 1 diabetes - an update. Expert Opinion on Biological Therapy. 2010;10(2):265-72. 
[77] Chen W, Syldath U, Bellmann K, Burkart V, Kolb H. Human 60-kDa heat-shock protein: a danger signal to the innate immune system. Journal of Immunology. 1999;162(6):3212-9.

[78] Nussbaum G, Zanin-Zhorov A, Quintana F, Lider O, Cohen IR. Peptide p277 of HSP60 signals $\mathrm{T}$ cells: inhibition of inflammatory chemotaxis. Int Immunol. 2006;18(10):1413-9.

[79] Quintana FJ, Carmi P, Cohen IR. DNA vaccination with heat shock protein 60 inhibits cyclophosphamide-accelerated diabetes. Journal of Immunology. 2002;169(10): 6030-5.

[80] Santos RR Junior, Sartori A, Lima DS, Souza PR, Coelho-Castelo AA, Bonato VL, Silva CL. DNA vaccine containing the mycobacterial hsp65 gene prevented insulitis in MLD-STZ diabetes. Journal of Immune Based Therapies and Vaccines. 2009;7(1):4.

[81] Santos Júnior RR, Sartori A, Bonato VL, Coelho Castelo AA, Vilella CA, Zollner RL, Silva CL. Immune modulation induced by tuberculosis DNA vaccine protects nonobese diabetic mice from diabetes progression. Clinical and Experimental Immunology. 2007;149(3):570-8.

[82] Ludvigsson J; Linköping Diabetes Immune Intervention Study Group. The role of immunomodulation therapy in autoimmune diabetes. Journal of Diabetes Science and Technology. 2009;3(2):320-30.

[83] Tisch R, Yang XD, Liblau RS, McDevitt HO. Administering glutamic acid decarboxylase to NOD mice prevents diabetes. Journal of Autoimmunity. 1994;7(6):845-50.

[84] Liu J, Filippova M, Fagoaga O, Nehlsen-Cannarella S, Escher A. Intramuscular injection of plasmid DNA encoding intracellular or secreted glutamic acid decarboxylase causes decreased insulitis in the nonobese diabetic mouse. Gene Therapy and Molecular Biology. 1999; 3: 197-206.

[85] Filippova M, Liu J, Escher A. Effects of plasmid DNA injection on cyclophosphamide-accelerated diabetes in NOD mice. DNA and Cell Biology. 2001;20(3):175-81.

[86] Weaver DJ Jr, Liu B, Tisch R. Plasmid DNAs encoding insulin and glutamic acid decarboxylase 65 have distinct effects on the progression of autoimmune diabetes in nonobese diabetic mice. Journal of Immunology. 2001;167(1):586-92.

[87] Tisch R, Wang B, Weaver DJ, Liu B, Bui T, Arthos J, Serreze DV. Antigen-specific mediated suppression of beta cell autoimmunity by plasmid DNA vaccination. Journal of Immunology. 2001;166(3):2122-32.

[88] Balasa B, Boehm BO, Fortnagel A, Karges W, Van Gunst K, Jung N, Camacho SA, Webb SR, Sarvetnick N. Vaccination with glutamic acid decarboxylase plasmid DNA protects mice from spontaneous autoimmune diabetes and B7/CD28 costimulation circumvents that protection. Clinical Immunology. 2001;99(2):241-52. 
[89] Wolfe T, Bot A, Hughes A, Möhrle U, Rodrigo E, Jaume JC, Baekkeskov S, von Herrath $\mathrm{M}$. Endogenous expression levels of autoantigens influence success or failure of DNA immunizations to prevent type 1 diabetes: addition of IL-4 increases safety. European Journal of Immunology. 2002;32(1):113-21.

[90] Seifarth C, Pop S, Liu B, Wong CP, Tisch R. More stringent conditions of plasmid DNA vaccination are required to protect grafted versus endogenous islets in nonobese diabetic mice. Journal of Immunology. 2003;171(1):469-76.

[91] Li A, Escher A. Intradermal or oral delivery of GAD-encoding genetic vaccines suppresses type 1 diabetes. DNA and Cell Biology. 2003;22(4):227-32.

[92] Goudy KS, Wang B, Tisch R. Gene gun-mediated DNA vaccination enhances antigen-specific immunotherapy at a late preclinical stage of type 1 diabetes in nonobese diabetic mice. Clinical Immunology. 2008;129(1):49-57.

[93] Joussemet B, Vu AT, Sai P, Bach JM. Gene-gun biolistic immunization encoding glutamic acid decarboxylase: a model for studying Langerhans cell abnormalities and mimicry in the nonobese diabetic mouse. Annals of the New York Academy of Sciences. 2005;1051:613-25.

[94] Bresson D, Fradkin M, Manenkova Y, Rottembourg D, von Herrath M. Genetic-induced variations in the GAD65 T-cell repertoire governs efficacy of anti-CD3/GAD65 combination therapy in new-onset type 1 diabetes. Mol Ther. 2010 Feb;18(2):307-16.

[95] Reed JC. Dysregulation of apoptosis in cancer. Journal of Clinical Oncology. 1999;17(9):2941-53.

[96] Birge RB, Ucker DS. Innate apoptotic immunity: the calming touch of death. Cell Death and Differentiation. 2008;15(7):1096-102.

[97] Li AF, Hough J, Henderson D, Escher A. Co-delivery of pro-apoptotic BAX with a DNA vaccine recruits dendritic cells and promotes efficacy of autoimmune diabetes prevention in mice. Vaccine. 2004;22(13-14):1751-63.

[98] Li A, Ojogho O, Franco E, Baron P, Iwaki Y, Escher A. Pro-apoptotic DNA vaccination ameliorates new onset of autoimmune diabetes in NOD mice and induces foxp3+ regulatory T cells in vitro. Vaccine. 2006;24(23):5036-46.

[99] Li A, Chen J, Hattori M, Franco E, Zuppan C, Ojogho O, Iwaki Y, Escher A. A therapeutic DNA vaccination strategy for autoimmunity and transplantation. Vaccine. 2010 Feb 23;28(8):1897-904.

[100] Krieg AM. CpG motifs in bacterial DNA and their immune effects. Annual Review of Immunology. 2002;20:709-60.

[101] Guan Y, Zhang M, Li Y, Cao W, Ji M, Liu Y. Vaccination with IA-2 autoantigen can prevent late prediabetic nonobese diabetic mice from developing diabetes mellitus. Diabetes Res Clin Pract. 2012;95(1):93-7. 
[102] Rivas EI, Driver JP, Garabatos N, Presa M, Mora C, Rodriguez F, Serreze DV, Stratmann T. Targeting of a $\mathrm{T}$ cell agonist peptide to lysosomes by DNA vaccination induces tolerance in the nonobese diabetic mouse. J Immunol. 2011;186(7):4078-87. 
